\title{
Antitumor effect of combined NAMPT and CD73 inhibition in an ovarian cancer model
}

\author{
Giovanna Sociali1, ${ }^{1,}$, Lizzia Raffaghello2,*, Mirko Magnone ${ }^{1}$, Federica Zamporlini ${ }^{3}$, \\ Laura Emionite ${ }^{4}$, Laura Sturla ${ }^{1}$, Giovanna Bianchi ${ }^{2}$, Tiziana Vigliarolo ${ }^{1}$, Aimable \\ Nahimana ${ }^{5}$, Alessio Nencioni ${ }^{6}, 7$, Nadia Raffaelli ${ }^{3}$, Santina Bruzzone ${ }^{1}$ \\ ${ }^{1}$ Department of Experimental Medicine, Section of Biochemistry, and CEBR, University of Genova, 16132 Genova, Italy \\ ${ }^{2}$ Laboratorio di Oncologia Istituto G. Gaslini, 16147 Genova, Italy \\ ${ }^{3}$ Department of Agricultural, Food and Environmental Sciences, Polytechnic University of Marche, 60131 Ancona, Italy \\ ${ }^{4}$ Animal Facility, IRCCS AOU San Martino - IST Istituto Nazionale per la Ricerca sul Cancro, 16132 Genova, Italy \\ ${ }^{5}$ Service and Central Laboratory of Hematology, University Hospital of Lausanne, 1011-CHUV, Lausanne, Switzerland \\ ${ }^{6}$ Department of Internal Medicine, University of Genova, 16132 Genova, Italy \\ ${ }^{7}$ IRCCS A.O.U. San Martino IST, Istituto Nazionale per la Ricerca sul Cancro, 16132 Genova, Italy \\ *These authors contributed equally to this work
}

Correspondence to: Santina Bruzzone, e-mail: santina.bruzzone@unige.it

Keywords: NAMPT, CD73, NAD', ovarian cancer

Received: July 29, 2015

Accepted: November 16, 2015

Published: December 08, 2015

\section{ABSTRACT}

Nicotinamide phosphoribosyltransferase (NAMPT) is a crucial enzyme in the biosynthesis of intracellular NAD ${ }^{+}$. NAMPT inhibitors have potent anticancer activity in several preclinical models by depleting NAD ${ }^{+}$and ATP levels. Recently, we demonstrated that CD73 enables the utilization of extracellular $\mathrm{NAD}^{+} /$nicotinamide $^{2}$ mononucleotide (NMN) by converting them to Nicotinamide riboside (NR), which can cross the plasmamembrane and fuel intracellular NAD+ biosynthesis in human cells. These processes are herein confirmed to also occur in a human ovarian carcinoma cell line (OVCAR-3), by means of CD73 or NRK1 specific silencing. Next, we investigated the anti-tumor activity of the simultaneous inhibition of NAMPT (with FK866) and CD73 (with a, $\beta$-methylene adenosine 5'-diphosphate, APCP), in an in vivo human ovarian carcinoma model. Interestingly, the combined therapy was found to significantly decrease intratumor NAD ${ }^{+}$, NMN and ATP levels, compared with single treatments. In addition, the concentration of these nucleotides in ascitic exudates was more remarkably reduced in animals treated with both FK866 and APCP compared with single treatments. Importantly, tumors treated with FK866 in combination with APCP contained a statistically significant lower proportion of Ki67 positive proliferating cells and a higher percentage of necrotic area. Finally, a slight but significant increase in animal survival in response to the combined therapy, compared to the single agents, could be demonstrated. Our results indicate that the pharmacological inhibition of CD73 enzymatic activity could be considered as a means to potentiate the anti-cancer effects of NAMPT inhibitors. 


\section{INTRODUCTION}

Cells utilize nicotinamide adenine dinucleotide $\left(\mathrm{NAD}^{+}\right)$either as a coenzyme in redox reactions or as a substrate for $\mathrm{NAD}^{+}$-degrading enzymes, such as poly(ADP-ribose) polymerases (PARPs), ectocellular NAD ${ }^{+}$ases, including CD38 and sirtuins (SIRT1-7) [1]. Previously, our group reported that CD73, mostly known as the ectoenzyme dephosphorylating extracellular AMP to adenosine, is in fact also capable of degrading both $\mathrm{NAD}^{+}$ and NMN: specifically, CD73 degrades $\mathrm{NAD}^{+}$to NMN and AMP, which are subsequently dephosphorylated by the same enzyme to NR and adenosine, respectively [2].

$\mathrm{NAD}^{+}$metabolism plays a crucial role in the fate of tumor cells and cellular $\mathrm{NAD}^{+}$levels are the result of a fine balance between opposite processes of $\mathrm{NAD}^{+}$synthesis and degradation.

In mammalian cells, $\mathrm{NAD}^{+}$is mainly synthesized from nicotinamide (NAM) through a salvage pathway sequentially involving the enzymes NAM phosphoribosyltransferase (NAMPT), which produces NMN, and NMN adenylyltransferase, which synthesizes $\mathrm{NAD}^{+}$from NMN and ATP [3-5]. NAMPT is overexpressed in different types of cancer, including prostate, gastric, breast and ovarian cancer, gliomas, leukemia, lymphoma and myeloma [6, 7]. The mechanism by which NAMPT is fundamental in tumor progression certainly relies on the fact that $\mathrm{NAD}^{+}$is required for the activity of $\mathrm{NAD}^{+}$-metabolizing enzymes, such as PARP1, SIRT1, SIRT6 and CD38, all having different cancerpromoting abilities, such as genomic stability, secretion of pro-inflammatory cytokines, angiogenesis, motility and invasion [8-11].

NAMPT inhibitors, including FK866 and CHS828, have potent anticancer activity in several preclinical models of solid and hematologic cancers [6] by depleting $\mathrm{NAD}^{+}$and ATP levels and thereby leading to tumor growth inhibition [6-8, 12-15].

Despite their promise in preclinical models, in phase I/II clinical studies, FK866 and CHS828 essentially failed to show signs of a meaningful anticancer activity in patients with solid tumors [16]. Regarding safety of these compounds, the main forms of reported toxicity were thrombocytopenia, various gastrointestinal symptoms and lymphopenia [6]. Also based on these results, currently, there is a general agreement on the fact that NAMPT inhibitors should be administered in combination with other treatments, to increase their efficacy $[6,8]$. One suggested possibility is the combination of NAMPT inhibitors with PARP-activating chemotherapeutics, which should further enhance the decrease in intracellular $\mathrm{NAD}^{+}$content $[17,18]$. Based on an opposite rationale, NAMPT inhibition has also been proposed to synergize with PARP inhibitors in triple-negative breast cancer [19]. NAMPT inhibition was also found to increase the efficacy of Tumor Necrosis Factor-Related Apoptosis Inducing Ligand (TRAIL), HDAC inhibitors, P-glycoprotein-1 (Pgp) inhibitors and of Rituximab, an anti-CD20 antibody, in leukemia cells [20-23]. Finally, NAMPT inhibition enhanced the effect of radiation in an in vivo prostate cancer model [24].

A plausible explanation for the limited activity of single-agent NAMPT inhibitors as cancer therapeutics in clinical trials could be the presence in human body fluids of $\mathrm{NAD}^{+}$or $\mathrm{NAD}^{+}$precursors, including nicotinic acid (NA), NMN and NR, which could well substitute for the inhibited $\mathrm{NAD}^{+}$biosynthesis from NAM [25]. Indeed, $\mathrm{NAD}^{+}$and $\mathrm{NMN}$ have been detected in mammal plasma and fluids $[26,27]$. NAD ${ }^{+}$efflux from cells can occur through a non-specific cell death, or through $\mathrm{Cx} 43$ hemichannels, with a regulated mechanism [28, 29].

Recently, we demonstrated that endogenous CD73 enables the utilization of extracellular $\mathrm{NAD}^{+} / \mathrm{NMN}$ as a precursor for intracellular $\mathrm{NAD}^{+}$biosynthesis in human cells by converting $\mathrm{NAD}^{+} / \mathrm{NMN}$ to NR which, in turn, can cross the plasma membrane and be phosphorylated intracellularly to NMN [25]. In in vitro cell systems, we demonstrated that when CD73 is either silenced or pharmacologically inhibited, the salvage of FK866-treated cells by extracellular NMN is reduced [25].

An increased CD73 expression has been observed in several types of cancer, and the tumor microenvironment contains factors promoting CD73 expression [30]. High CD73 expression and activity confer a survival advantage to cancer cells, frequently determining metastasis and a poor prognosis [31]. Up to now, however, CD73 role in cancer has always been ascribed to the CD73-mediated extracellular production of adenosine and to the regulation of purinergic receptor activity [32-35]. Indeed, CD73 is considered an appealing therapeutic target for treating cancer and the CD73 inhibitor $\alpha, \beta$-methylene adenosine 5 '-diphosphate (APCP) shows promising anticancer activity, by inhibiting CD73-mediated functions in tumor cells and in T-cell immunity [33, 36, 37].

Epithelial ovarian cancer (EOC) is the most lethal gynecologic malignancy worldwide, with a 5-year survival of less than $30 \%$ for the women diagnosed at advanced stage [38]. Thus, advances in the identification of new therapeutical strategies are demanded.

Here, we investigated the anti-tumor potential of simultaneously inhibiting NAMPT (with FK866) and CD73 (with APCP) in an in vitro and in vivo human ovarian carcinoma model. Blocking CD73 would hamper the generation of NR to be used as an intracellular $\mathrm{NAD}^{+}$ precursor by cancer cells, thereby leading to a marked potentiation of FK866 anticancer effects (Figure 1A). 


\section{RESULTS}

\section{Identification of the $\mathrm{NAD}^{+}$biosynthetic pathways in OVCAR-3 cells}

The ovarian cancer cell line OVCAR-3 is an established model for in vivo studies of cancer therapeutics: their intraperitoneal inoculation leads to a local dissemination with formation of tumor masses and ascites, in which it is possible to measure the amount of extracellular metabolites. To verify that OVCAR-3 cells represented an appropriate model for our study, we preemptively assessed i) the $\mathrm{NAD}^{+}$biosynthetic pathways that are active in these cells, ii) their sensitivity to FK866, and iii) the expression of CD73.

Since $\mathrm{NAD}^{+}$can be synthesized from various precursors and through different pathways [5], we screened which of these pathways are present in
OVCAR-3 cells. Specifically, the activities of NAMPT (converting NAM to NMN), nicotinamide riboside kinase (NRK; phosphorylating NR to NMN), and of nicotinate phosphoribosyltransferase (NAPRT; converting NA to NAMN), were measured in OVCAR-3 cell extracts. In addition, the activity of quinolinate phosphoribosyltransferase (QAPRT), involved in the de-novo synthesis of $\mathrm{NAD}^{+}$from tryptophan, was also tested. As shown in Figure 1B, both NAMPT and NRK activities could be detected in OVCAR-3 cells, indicating that these cells are able to use both NAM and NR as $\mathrm{NAD}^{+}$precursors. In humans, NRK activity is expressed by two different isoforms, which can be enzymatically distinguished based on kinetic parameters [39]. The fact that the NRK activity in OVCAR-3 cell lysates, as assessed in the presence of $72 \mu \mathrm{M} \mathrm{NR}$, was similar to the one measured in the presence of 36 or $18 \mu \mathrm{M} \mathrm{NR}$, i.e. below the $\mathrm{K}_{\mathrm{m}}$ for NR of the NRK2 isoform $(46 \mu \mathrm{M}$,

\section{A}
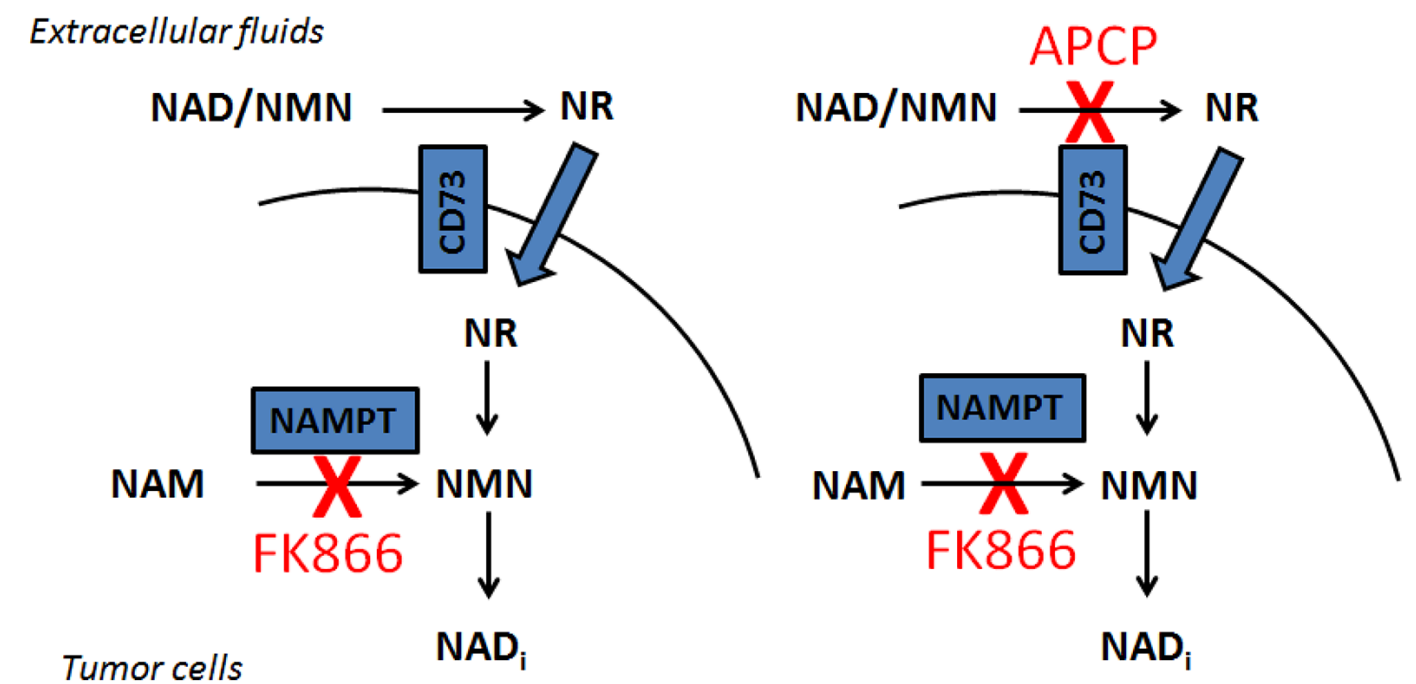

B

C
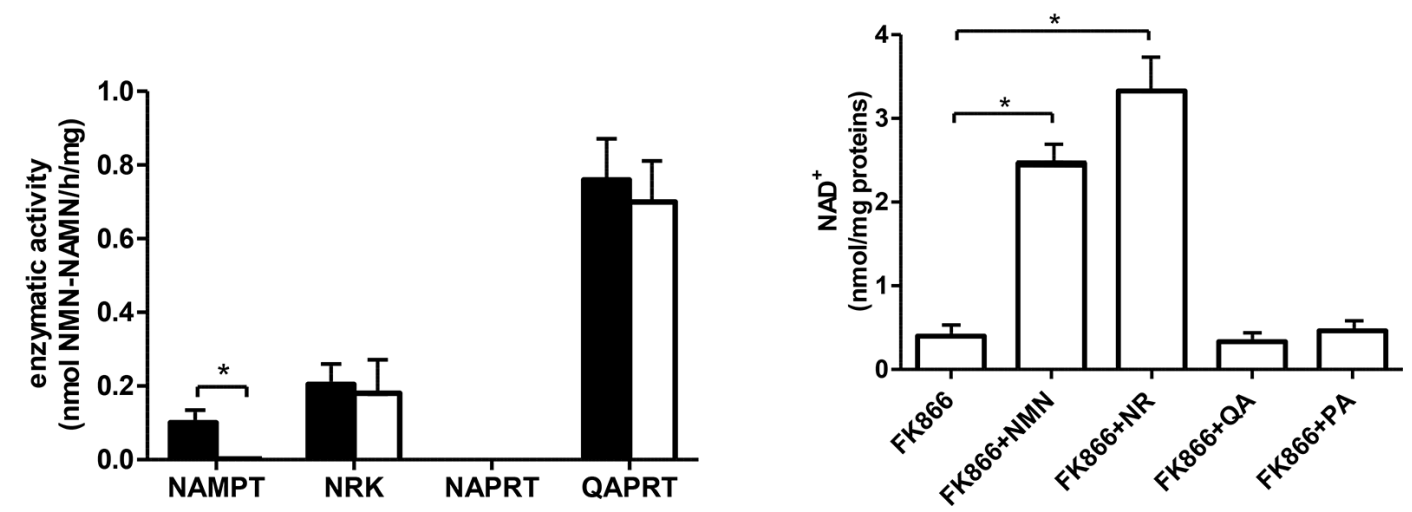

Figure 1: OVCAR-3 cells are sensitive to NAMPT inhibition with FK866. (A) Schematic representation of the rationale for simultaneously inhibiting CD73 and NAMPT. (B) Screening of the NAD biosynthetic enzyme activities performed on cell lysates from untreated OVCAR-3 cells (black bars) or from cells treated for $24 \mathrm{~h}$ with $30 \mathrm{nM}$ FK866 (white bars). Results are mean \pm SD of 3 determinations. ${ }^{*} p<0.001$. (C) OVCAR-3 cells were incubated for $48 \mathrm{~h}$ with $30 \mathrm{nM}$ FK866, in the presence of $10 \mu \mathrm{M} \mathrm{NMN}$, NR, QA or of $100 \mu \mathrm{M}$ PA. Results are mean \pm SD of at least 3 determinations. ${ }^{*} p<0.01$ compared to FK866 alone. 
ref. 39), indicates that the main NRK activity is due to the expression of NRK1 $\left(\mathrm{K}_{\mathrm{m}}\right.$ for $\mathrm{NR}, 3.4 \mu \mathrm{M}$, ref. 39) (Supplementary Figure S1). When OVCAR-3 cells were incubated for $24 \mathrm{~h}$ in the presence of FK866, NAMPT activity was almost completely inhibited, whereas the other enzymatic activities were not affected (Figure 1B): thus, NAMPT inhibition with FK866 does not alter the enzymatic activity of the other enzymes involved in $\mathrm{NAD}^{+}$synthesis. The intracellular $\mathrm{NAD}^{+}$concentration was greatly reduced by a $48 \mathrm{~h}$-incubation with 30 $\mathrm{nM}$ FK866 (from $19.12 \pm 4.88$ to $0.40 \pm 0.12 \mathrm{nmol} /$ $\mathrm{mg}$ proteins), indicating a major role for the NAMPTmediated $\mathrm{NAD}^{+}$production in OVCAR-3 cells. The exogenous addition of NMN or NR reverted FK866induced $\mathrm{NAD}^{+}$reduction (Figure 1C). NAPRT activity was not detectable in these cell extracts, whereas QAPRT was the most abundant activity (Figure 1B). The de-novo route controlled by QAPRT is considered not relevant in most cell types, under physiological conditions [5]. To analyze the contribution of QAPRT activity to NAD maintenance in OVCAR-3 cells, cells were incubated in the presence of quinolinic acid (QA). No increase in their intracellular $\mathrm{NAD}^{+}$concentration was observed in control $(20.80 \pm 3.52 \mathrm{nmol} / \mathrm{mg}$ proteins) or in FK866-treated cells (Figure 1C). Accordingly, addition of phthalic acid (PA), a QAPRT inhibitor, failed to affect the intracellular $\mathrm{NAD}^{+}$levels under either type of treatment conditions (control+ phthalic acid: $20.98 \pm 2.87 \mathrm{nmol} / \mathrm{mg}$ proteins; FK866+ phthalic acid: Figure 1C). All together, these results indicate that in OVCAR-3 cells QAPRT does not significantly contribute in maintaining $\mathrm{NAD}^{+}$levels. The significance of the marked QAPRT activity measured in the lysate of these cells remains to be elucidated. The possibility that during the preparation of the lysate an inhibitory factor of the enzyme has been removed or diluted cannot be ruled out, as occurred in [40]. In this view, in ovarian carcinoma cells, QAPRT activity might become relevant to $\mathrm{NAD}^{+}$production only under specific, still unknown conditions. For instance, it has been reported that neoplastic transformation in astrocytes is associated with a QAPRT-mediated switch in $\mathrm{NAD}^{+}$synthesis, whereby glioma cells begin to utilize microglia-derived $\mathrm{QA}$ as an alternative $\mathrm{NAD}^{+}$precursor thereby acquiring resistance to radiochemotherapy [41].

\section{CD73 inhibition reduces the NMN-mediated rescue of FK866-induced death in OVCAR-3 cells}

Next, we assessed CD73 expression in OVCAR-3 cells. At first, we evaluated the presence of ectocellular AMP-degrading activity, which was $71.9 \pm 12.1 \mathrm{nmol}$ adenosine $/ \mathrm{min} / \mathrm{mg}$ protein, as measured using intact cells. A qPCR analysis also confirmed presence of CD73 mRNA in OVCAR-3 cells, which was reduced by $85 \%$ at $24 \mathrm{~h}$ after transfection with CD73-siRNA
(Figure 2A). In accordance, Western blot analysis on cell lysates from OVCAR-3 cells, also revealed a band approximately at a $70 \mathrm{kDa}$ molecular weight, which was decreased by $65 \%$ in cells transfected with CD73-siRNA (Figure 2B). CD73-silencing greatly reduced the AMP-degrading activity (Figure 2C), confirming that this enzymatic activity reflected the presence of CD73, and not of other enzymes. Finally, CD73 expression on intact cells was also demonstrated by FACS analysis (Supplementary Figure S2). Since extracellular $\mathrm{NAD}^{+} / \mathrm{NMN}$ might also be a substrate for CD38, being hydrolyzed to NAM [25, 42], we evaluated CD38 enzymatic activities in OVCAR-3 cells: however, no detectable production of NAM and ADPR from $\mathrm{NAD}^{+}$, nor of NAM and cyclic-GDP-ribose from $\mathrm{NGD}^{+}$ (a NAD ${ }^{+}$analogue used to measure the CD38-mediated ADP-ribosyl cyclase activity, ref. 43) could be detected (data not shown).

We previously showed that, in U87 (human glioblastoma) and A549 (human lung) cells, CD73 silencing or its pharmacological inhibition with APCP prevented the rescue from FK866 cytotoxicity by NMN supplementation [25]. In line with this observation, CD73silencing reduced by $70 \%$ the ability of FK866-treated OVCAR-3 cells to generate intracellular $\mathrm{NAD}^{+}$using extracellular NMN (Figure 2D).

The presence of $30 \mathrm{nM}$ FK 866 for $72 \mathrm{~h}$ in the culture media greatly reduced (by approximately 90\%) OVCAR-3 cell viability, and extracellular NMN completely rescued cells from the FK866-induced cell death (Figure 2E, control cells), as previously shown for other cell lines [25]. When CD73 expression was down-regulated, the NMNmediated rescue of the FK866-induced cell death was significantly reduced (Figure 2E). Similar measurements of cell viability in the presence of the specific CD73 inhibitor APCP, indicated that APCP per se did not affect viability of control or of FK866-treated cells, whereas it significantly alleviated the protective effects of exogenously added NMN on FK866-treated malignant cells (Figure 2F). These data indicate that CD73 activity is necessary for utilization of extracellular NMN to fuel intracellular $\mathrm{NAD}^{+}$synthesis and thereby rescue cells from the FK866-induced cell death.

To conclusively demonstrate that NMN, in order to be utilized by cells, is converted into NR, which can cross the plasmamembrane through a dypiridamoleinhibitable nucleoside transporter [44], OVCAR-3 cells were incubated, or not, with FK866, NR, or NMN, with or without dypiridamole. Dypiridamole almost completely abrogated the NR-mediated rescue of FK866-treated cells and greatly inhibited the rescue obtained with NMN, both in terms of intracellular $\mathrm{NAD}^{+}$content (Figure $3 \mathrm{~A}$ ) and of cell viability (Figure 3B). The effects of dypiridamole are in line with the idea that NR influx into cells has to occur to ensure cell rescue from FK866 by NMN (or NR itself). Finally, NRK1 expression was specifically silenced 
in OVCAR-3 cells: qPCR analysis performed $24 \mathrm{~h}$ after transfection with NRK1-specific siRNA demonstrated a $65 \pm 15 \%(n=3)$ reduction in NRK1 mRNA levels. In

A

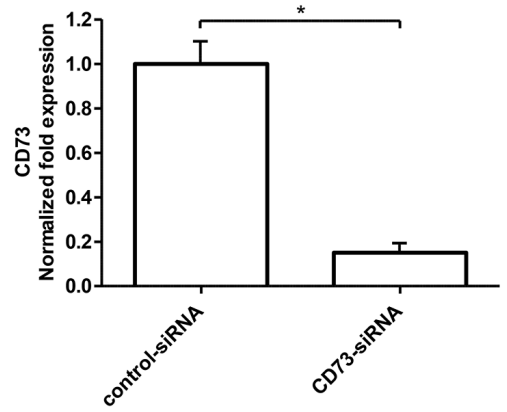

B
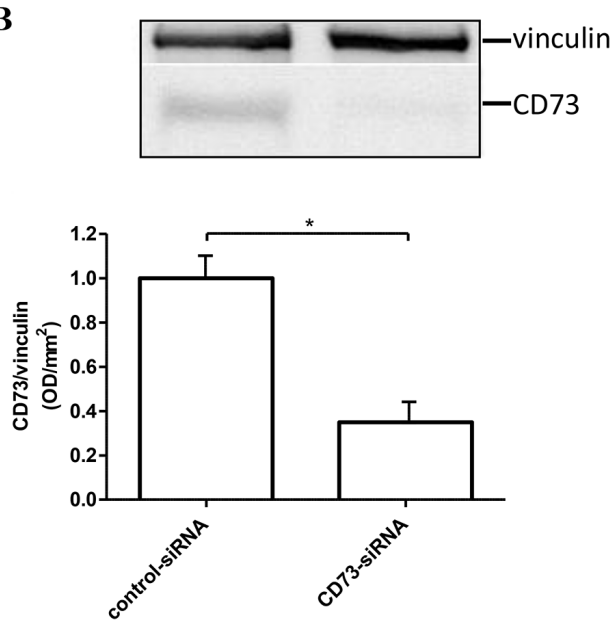

C

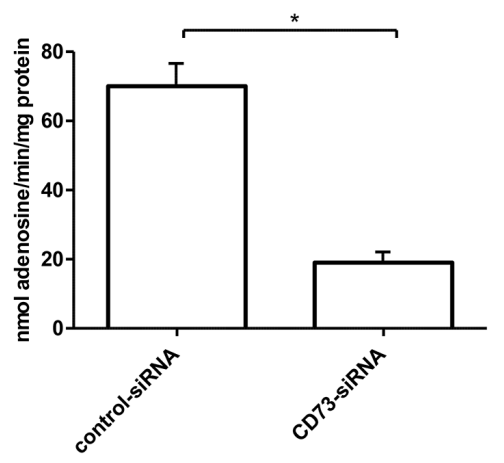

NRK1-silenced cells, both NR- and NMN-mediated rescue from FK866-induced NAD ${ }^{+}$depletion (Figure 3C) and cell death (Figure 3D) were potently and significantly reduced.

D

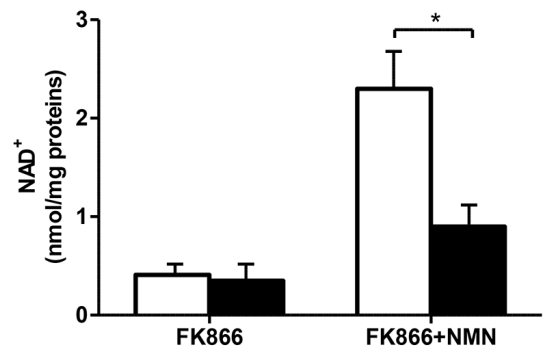

$\mathbf{E}$

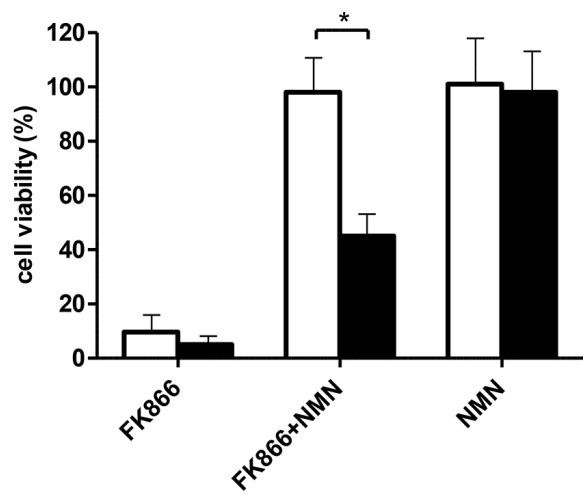

F

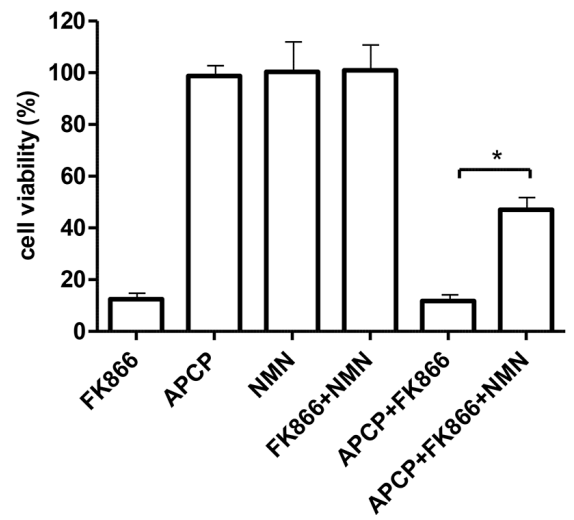

Figure 2: Silencing of CD73 expression or pharmacological CD73 inhibition impairs the NMN-mediated rescue from FK866-induced cell death. (A-E) OVCAR-3 cells were transfected in the presence of a specific CD73-siRNA or negative controlsiRNA (control-siRNA). Twenty four hours after transfection: qPCR analysis (A), Western blot analysis (B), and evaluation of the AMPdegrading activity (C) were performed; (D-E) After $24 \mathrm{~h}$ after electroporation, cells transfected with control-siRNA (white bars), or with CD73-siRNA (black bars), were treated (or not) with $30 \mathrm{nM} \mathrm{FK866,} \mathrm{in} \mathrm{the} \mathrm{presence} \mathrm{or} \mathrm{absence} \mathrm{of} \mathrm{NMN} \mathrm{(added} \mathrm{twice/day} \mathrm{at} 10 \mu \mathrm{M}$ final concentration) and $\mathrm{NAD}^{+}$content (D) and cell viability (E) were evaluated after 48 and $72 \mathrm{~h}$, respectively. Cell viability is expressed as \% of untreated cells. Data are mean $\pm \mathrm{SD}(n=3)$. In panel B, one representative blot and the mean $\pm \mathrm{SD}$ of 3 different analysis are shown $* p<0.05$. (F). OVCAR-3 cell viability $\left(5 \times 10^{3}\right.$ well in 96 -well plates $)$ was evaluated after $72 \mathrm{~h}$ incubation of the cells in complete medium with or without $30 \mathrm{nM}$ FK866, in the presence or absence of $1 \mu \mathrm{M}$ adenosine 5 '-( $\alpha, \beta$-methylene)diphosphate (APCP), or of $10 \mu \mathrm{M}$ NMN (added twice a day). Results are expressed as percentage of cell growth relative to untreated, control cells. Data are expressed as mean \pm $\mathrm{SD}(n=3) .{ }^{*} p<0.05$, compared to FK866 ${ }^{+} \mathrm{NMN}$-treated cells. 
A

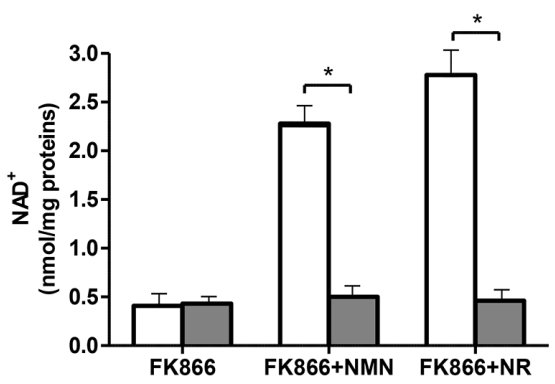

B

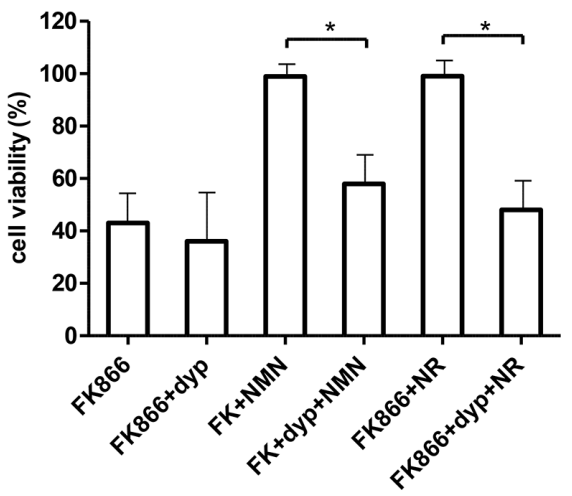

C

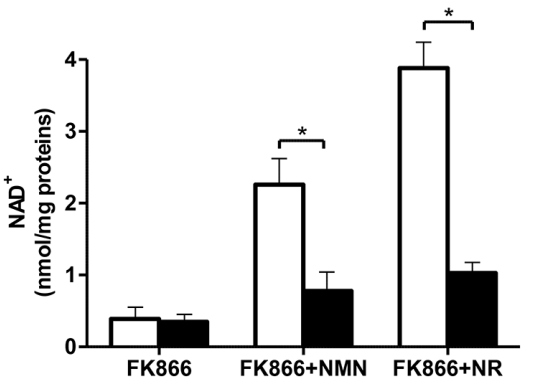

$\mathbf{D}$

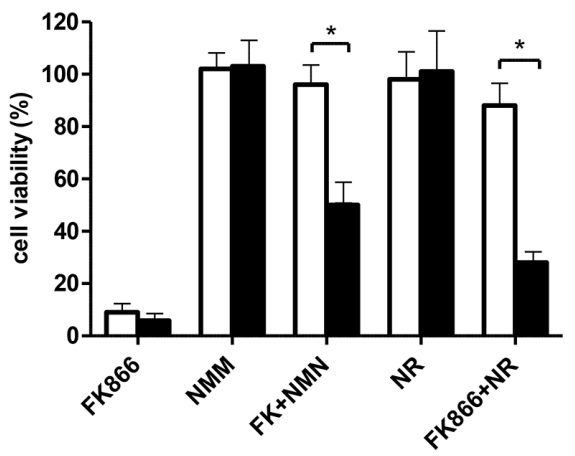

Figure 3: Inhibition of NR transport or silencing of NRK1 expression impairs the NMN-mediated rescue from FK866induced NAD ${ }^{+}$depletion and cell death. (A-B) OVCAR-3 cells were incubated for $48 \mathrm{~h}$ in the presence of $30 \mathrm{nM}$ FK866, with (grey bars) or without (white bars) $5 \mu \mathrm{M}$ dipyridamole (dyp) and NMN or NR (added twice/day at $10 \mu \mathrm{M}$ final concentration), as indicated. $\mathrm{NAD}^{+}$content (A) and cell viability (B) were evaluated after $48 \mathrm{~h}$. Cell viability was expressed as relative to control, untreated cells. (C, D) OVCAR-3 cells were transfected in the presence of a specific NRK1-siRNA (black bars) or negative control-siRNA (white bars). Twenty four hours after transfection, cells were treated (or not) with $30 \mathrm{nM} \mathrm{FK} 866$, in the presence or absence of NMN or NR (added twice/ day at $10 \mu \mathrm{M}$ final concentration): $\mathrm{NAD}^{+}$content (C) and cell viability (D) were evaluated after $48 \mathrm{~h}$ and $72 \mathrm{~h}$, respectively. Results are the mean $\pm \mathrm{SD}$ of at least 3 independent determinations. ${ }^{*} p<0.05$. 


\section{Combined treatment with NAMPT and CD73 inhibitors affects tumor NAD ${ }^{+}, \mathbf{N M N}$ and ATP content}

The data obtained in vitro in OVCAR-3 cells suggested that this cell line was suitable for investigating whether the simultaneous administration of FK866 and APCP would result in a more robust reduction in the intracellular $\mathrm{NAD}^{+}$content in an in vivo cancer model. Thus, an in vivo experiment was conducted utilizing athymic nude mice that were inoculated intraperitoneally with OVCAR-3 cells stably transfected with fireflyluciferase. The expression of firefly-luciferase by the cancer cells allowed us to monitor tumor development by in vivo bioluminescence using the IVISTM Imaging System. Mice were randomized to the following treatment groups: vehicle, FK866, APCP or the combination of the two molecules. Animals were treated for 28 days: body weight measurements and general physical status recordings indicated the absence of major toxicities as a result of these treatments throughout the treatment period.

$\mathrm{NAD}^{+}, \mathrm{NMN}$ and ATP levels were evaluated both in the recovered tumor mass and in ascitic exudates. $\mathrm{NAD}^{+}$ content in the tumors was more pronouncedly decreased in animals treated with the combination of the two molecules than with FK866 alone (Figure 4A), confirming that NAMPT and CD73 inhibition affect two different pathways of intracellular $\mathrm{NAD}^{+}$biosynthesis. Consistent with these data, NMN levels within tumor masses were found to be significantly reduced in the combination treatment arm, as compared to those measured in mice that had been treated with FK866 alone (Figure 4B), which is in keeping with the involvement of NMN as an intermediate metabolite of both NAMPT- and NRK-mediated pathways of $\mathrm{NAD}^{+}$production (Figure 1A). Finally, intratumor ATP levels were also strongly decreased by the simultaneous inhibition of NAMPT and CD73 (Figure 4C), which is consistent with previous studies reporting that inhibition of NAD ${ }^{+}$biosynthesis also affects ATP content $[14,45]$. APCP alone did not significantly decrease intratumor $\mathrm{NAD}^{+}, \mathrm{NMN}$ and ATP levels, as compared to control animals (Figure 4), suggesting that, under baseline conditions, within a tumor, $\mathrm{NAD}^{+}$is primarily synthesized from NAM.

Next, since the presence of extracellular $\mathrm{NAD}^{+}$and/ or NMN in the fluids surrounding the tumor represents a fundamental pre-requisite to verify the hypothesis that interfering with the utilization of extracellular $\mathrm{NAD}^{+} /$ NMN by inhibiting CD73 activity could enhance the anti-tumor activity of FK866, we measured $\mathrm{NAD}^{+}$and NMN levels in the ascitic exudates collected from the animals at sacrifice. Indeed, both $\mathrm{NAD}^{+}$and $\mathrm{NMN}$ could be detected in the untreated controls (Figure 4D, 4E). In animals treated with the combination therapy, both $\mathrm{NAD}^{+}$ and NMN levels were strongly reduced, indicating that the levels of extracellular nucleotides indeed mirror the intracellular values (Figure 4D, 4E). In FK866-treated animals, $\mathrm{NAD}^{+}$and, more remarkably, NMN levels were decreased compared to those measured in exudates from control animals (Figure 4D, 4E). ATP levels were significantly lower in exudates from animals treated with the combination therapy, as it was observed for the intracellular ATP content. The observation of higher ATP levels in APCP-treated animals (Figure 4F) could be explained by the absence of downstream AMP degradation to adenosine due to CD73 inhibition by APCP.

Interestingly, NR was indeed detectable in ascitic exudates, which is in agreement with the presence of the ectocellular CD73 activity in tumor cells. Low NR values, ranging from $3 \mathrm{nM}$ to $68 \mathrm{nM}$, were measured in the tested samples, which might suggest a marked uptake of extracellular NR [44]. A high degree of variability in NR levels was observed within ascitic exudates within group of treatment, which might reflect NR values that were very close to the detection limit of our method. As a result, no comparison between the different treatments under this respect (effects on extracellular NR levels) was possible.

\section{Simultaneous administration of NAMPT and CD73 inhibitors differently affects $\mathrm{NAD}^{+}$content in hearts and livers}

The effects of the different treatments were also evaluated by measuring $\mathrm{NAD}^{+}$levels in hearts and livers. As shown in Figure 5A, the pattern of NAD levels in the heart after the different treatments essentially paralleled the $\mathrm{NAD}^{+}$levels that were detected in the tumors. FK866 treatment significantly reduced intracellular $\mathrm{NAD}^{+}$levels in hearts (Figure 5A), in line with a previous report [46]. Interestingly, CD73 activity appeared to be relevant for the maintenance of intracellular $\mathrm{NAD}^{+}$content in the heart, too, since the simultaneous inhibition of NAMPT and CD73 decreased heart $\mathrm{NAD}^{+}$levels to a higher extent as compared to NAMPT inhibition alone (Figure 5A).

In contrast with what observed in tumors and hearts, treatment with FK866 increased NAD ${ }^{+}$levels in the liver (Figure 5B). This observation is in agreement with results obtained with a different NAMPT inhibitor (administered to mice for 5 days), which also did not reduce liver $\mathrm{NAD}^{+}$ content [47]. However, simultaneous inhibition of CD73 and NAMPT did significantly reduce (by approximately $25 \%$ ) liver $\mathrm{NAD}^{+}$content as compared to the $\mathrm{NAD}^{+}$ content measured in FK866-treated animals.

\section{In vivo antitumor effect of NAMPT and CD73 inhibition}

We next aimed to evaluate the effect of combined NAMPT and CD73 inhibition on tumor cell proliferation and necrosis. To this end, we carried out immunohistochemical analyses on paraffin-embedded tissue sections of tumors 
A

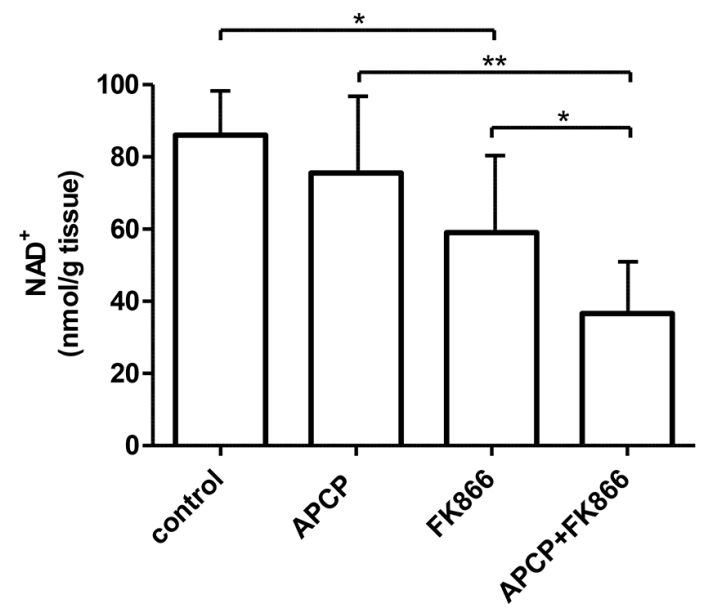

B

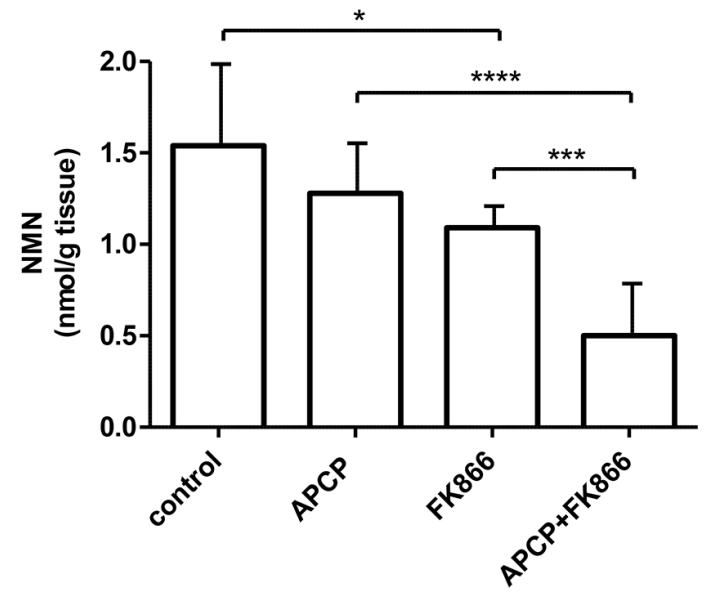

C

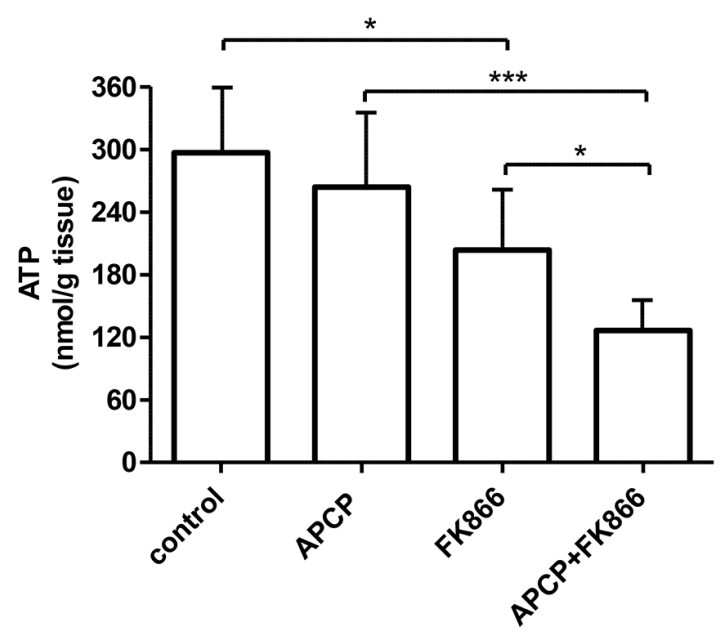

D

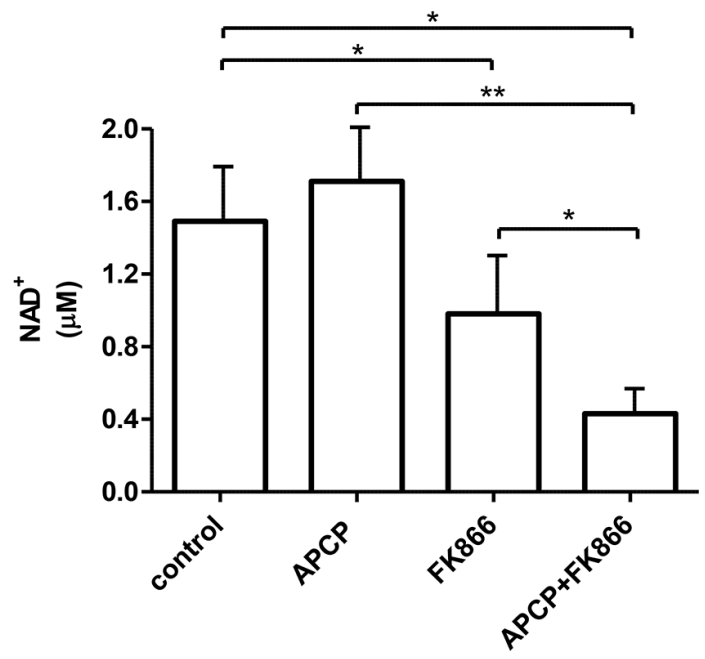

$\mathbf{E}$

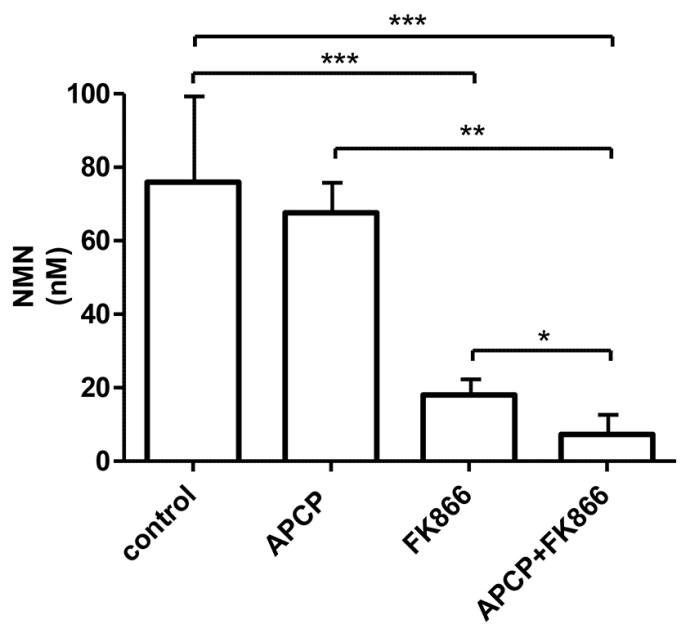

$\mathbf{F}$

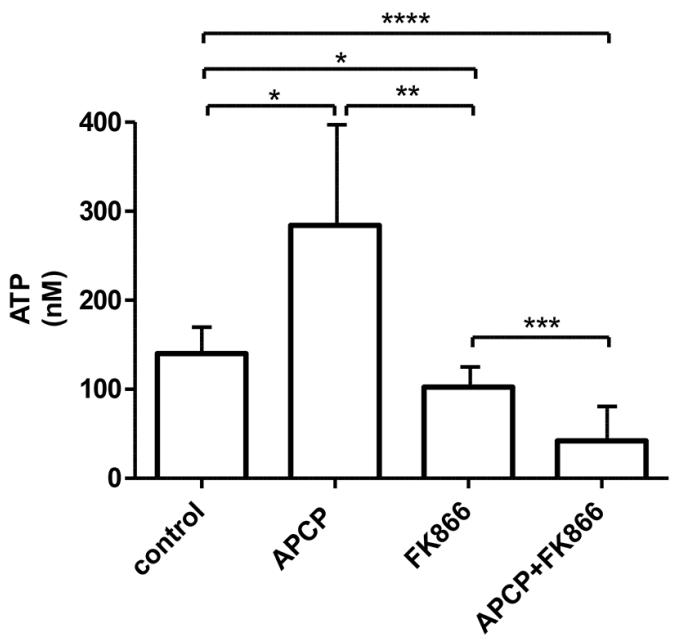

Figure 4: $\mathrm{NAD}^{+}, \mathrm{NMN}$ and $\mathrm{ATP}$ levels in tumors and in ascitic exudates from control and treated mice. $\mathrm{NAD}^{+}(\mathrm{A}, \mathrm{D})$, NMN (B, E) and ATP (C, F) levels were measured in tumors (A, B, C) or in ascitic exudates (D, E, F) recovered from the animals treated with vehicle (control), or FK866 or APCP or their combination. Results represent the mean \pm SD (tumors, $n=8$; ascitic exudates, at least $n=5) .{ }^{*} p<0.05 ;{ }^{*} p<0.01 ;{ }^{* * *} p<0.001 ;{ }^{* * * *} p<0.0001$. 
from animals treated (or not) with FK866, APCP, or FK866 plus APCP for 28 days. As shown in Figure 6A, FK866 plus APCP-treated tumors contained a statistically significant lower proportion of Ki67 positive proliferating cells compared to control tumors. A representative staining with anti-Ki67 mAb of tumors from the different treatment arms is shown in Figure 6A. Histological analysis of paraffin-embedded sections from control tumor and treated tumors demonstrated that the percentage of necrosis was significantly increased in both FK866- and APCP-treated tumors, but the most potent effect was documented in the combination treatment arm (Figure 6B).

Finally, the combination FK866 plus APCP was the only treatment that significantly, albeit slightly, improved mice survival compared to vehicle (Figure 6C).

\section{DISCUSSION}

Lowering intratumor $\mathrm{NAD}^{+}$concentration is currently considered a promising strategy to treat cancer and major efforts are directed to the identification of clinically applicable NAMPT inhibitors [6-8, 13, 48].
In this study, we investigated whether the beneficial antitumor effects of NAMPT inhibition could be circumvented in vivo by the presence of $\mathrm{NAD}^{+}$or $\mathrm{NAD}^{+}$ precursors, such as NMN or NR in the extracellular milieu, since these metabolites can potentially fuel $\mathrm{NAD}^{+}$ production through alternative pathways [25]. Several lines of evidence obtained in vitro, demonstrated that in OVCAR-3 cells, similarly to what previously reported for U87 and A549 cells [25], CD73 expression also generates NR from extracellular NMN, circumventing the anticancer effects of NAMPT inhibition. Specifically, the NMNmediated rescue from FK866-induced $\mathrm{NAD}^{+}$depletion and cell death were impaired by: i) CD73 silencing or inhibition with APCP (Figure 2D, 2E, 2F); ii) inhibition of NR transport (Figure 3A, 3B); iii) NRK1 silencing (Figure 3C, 3D). The fact that, in FK866-treated cells, NMN completely rescued cells from death (Figures 2E, $2 \mathrm{~F}$ and $3 \mathrm{~B}, 3 \mathrm{D})$, while increasing $\mathrm{NAD}^{+}$content above $10 \%$ of the control value (Figures $1 \mathrm{C}, 2 \mathrm{D}, 3 \mathrm{~A}, 3 \mathrm{C}$ ), and not to a complete restoration to values in untreated cells (i.e. approximately $20 \mathrm{nmol} / \mathrm{mg}$ proteins), is in line with the observation that cell death occurs when $\mathrm{NAD}^{+}$levels are depleted to less than 5\% [45].

A

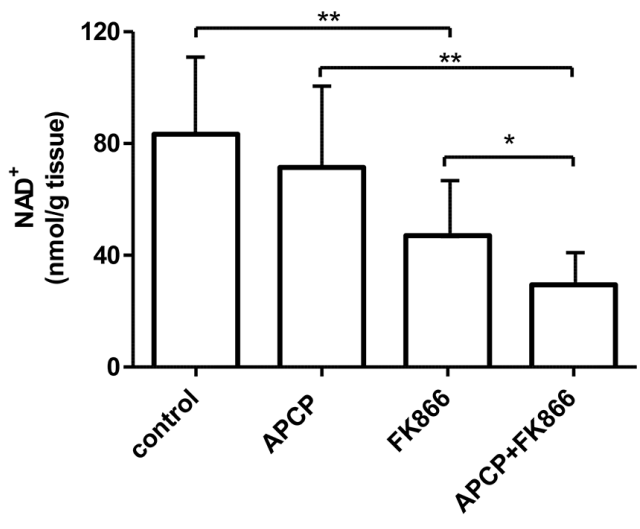

B

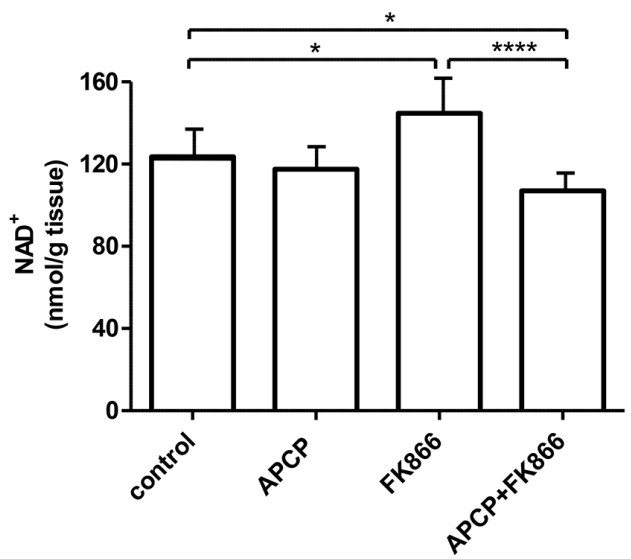

Figure 5: $\mathrm{NAD}^{+}$levels in hearts and livers from control and treated mice. $\mathrm{NAD}^{+}$levels were measured in hearts $(\mathrm{A})$ and livers (B) recovered from the animals treated with vehicle (control), or FK866 or APCP or their combination. Results are expressed as nmol/g tissue and represent the mean $\pm \mathrm{SD}(n=8) .{ }^{*} p<0.05 ; * * p<0.01 ; * * * * p 0.0001$. 
The most relevant result obtained in this study is represented by the proof of concept that the combined inhibition of NAMPT and CD73 indeed results in a significant reduction in $\mathrm{NAD}^{+}$and $\mathrm{NMN}$ concentration in tumors in vivo (Figure 4), leading to a reduced tumor cell proliferation, increased necrotic tumor cell death and to a significant, albeit small, advantage in terms of survival (Figure 6).

The results on $\mathrm{NAD}^{+}$levels in tumors, heart and liver indicate that also in vivo, the intracellular $\mathrm{NAD}^{+}$ content is quantitatively related to the ectoenzymatic activity of CD73, as previously demonstrated in vitro in

A

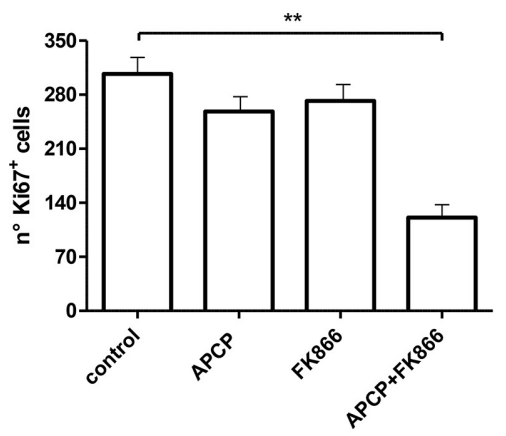

B

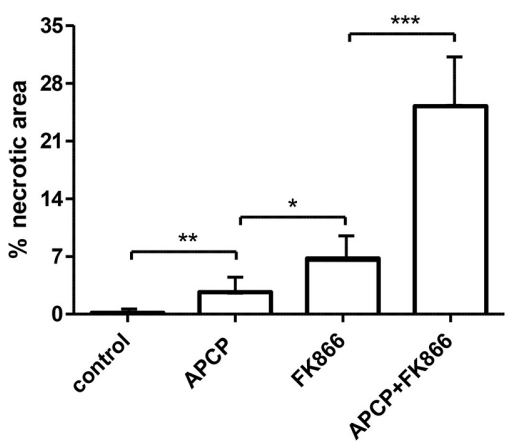

C

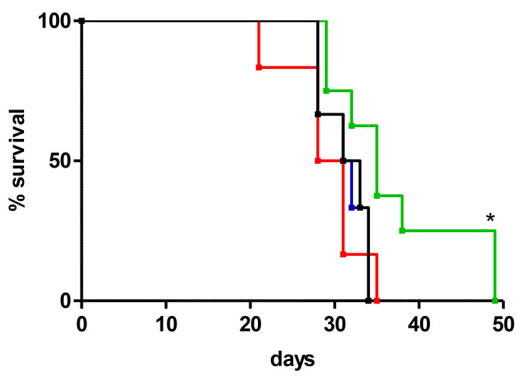

different cell lines [25]. The contribution of the different $\mathrm{NAD}^{+}$biosynthetic pathways and the relevance of the utilization of extracellular $\mathrm{NAD}^{+}$precursors to $\mathrm{NAD}^{+}$ synthesis may differ among different organs and tissues. In the heart, NAMPT inhibition determined a significant decrease in the intracellular $\mathrm{NAD}^{+}$content (Figure 5), in agreement with our previous findings [46] and with our previous observation that NAMPT activity is a key contributor to $\mathrm{NAD}^{+}$synthesis in this organ [49]. The concomitant inhibition of CD73 by APCP determined a further decrease of the intracellular $\mathrm{NAD}^{+}$content, indicating that also in heart CD73 enzymatic activity
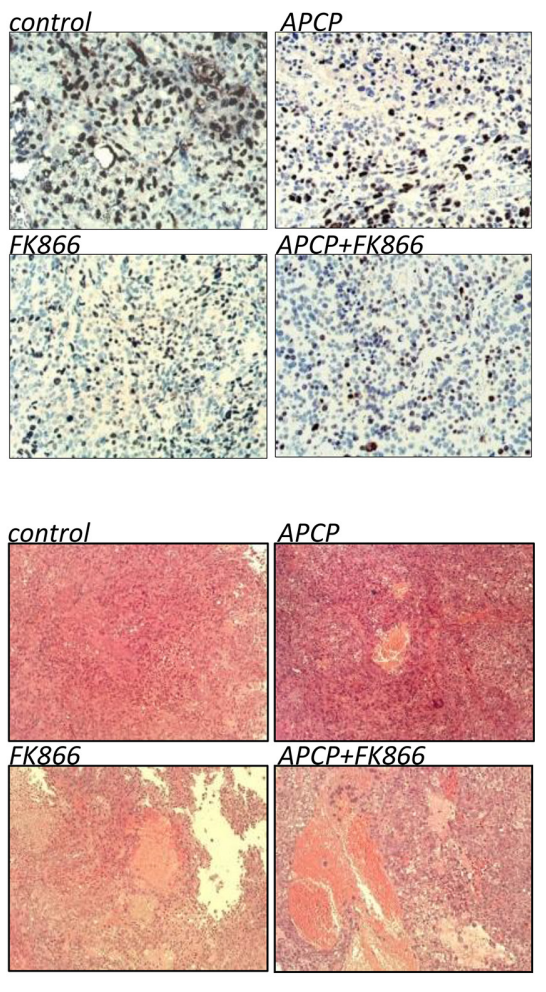

Figure 6: Antitumor effects of administration of FK866, APCP and FK866 ${ }^{+}$APCP in OVCAR- 3 bearing mice. (A, B) Tumors were collected from animals treated for 28 days with vehicle (control), or FK866 or APCP or their combination: tumor tissue sections were stained with an anti-Ki67 antibody (A) or with Hematoxilyn/Eosin solution (B); the number of Ki67 cells was evaluated in randomly chosen fields from different samples $(n=5$ fields/sample); the necrotic areas were quantified using the Image J program and results represent the percentage of necrotic area relative to the total section and are the mean \pm SD of at least 4 samples. ${ }^{*} p<0.05 ; * * p<0.01 ; * * * p<$ 0.001. Representative images are shown. (C) Animals were treated with vehicle (control, black), or FK866 (blue) or APCP (red) or their combination (green) and were sacrificed when they showed signs of poor health. Survival curves were constructed by using the KaplanMeier method. Statistical analysis of different treatment groups was performed by Peto's log-rank test. * $p<0.05$ vs black, blue and red lines. 
contributes to the generation of intracellular $\mathrm{NAD}^{+}$. Indeed, the presence of a NRK activity has been demonstrated in this organ [49]. Conversely, in the liver, FK866 failed to cause a reduction in $\mathrm{NAD}^{+}$content, in agreement with previous reports, in which the relevance of circulating levels of metabolites, other than NAM, fueling $\mathrm{NAD}^{+}$synthesis in this organ is suggested, and in which the presence of a robust activity of the enzymes responsible for their conversion to $\mathrm{NAD}^{+}$is proven [46, 49]. The fact that the simultaneous inhibition of CD73 and NAMPT significantly reduces (by approximately $25 \%$ ) hepatic $\mathrm{NAD}^{+}$content, compared to the content in FK866treated animals (Figure 5B), indicates a contribution by CD73-mediated extracellular NR generation to $\mathrm{NAD}^{+}$ biosynthesis in this organ. Consistent with this notion, the presence of a NRK activity has been previously demonstrated in the liver [49] and NR supplementation to mice was found to increase $\mathrm{NAD}^{+}$content in liver, muscle and brown adipose tissue [50]. Thus, NAMPT contribution to intracellular $\mathrm{NAD}^{+}$levels appears to vary between different organs, tissues and tumors. In the case of the tumor cells used for this study, NAMPT and NRK seem to play a major role in $\mathrm{NAD}^{+}$biosynthesis, as the simultaneous inhibition of NAMPT and CD73 significantly decreased intracellular $\mathrm{NMN}$ and $\mathrm{NAD}^{+}$ concentration (Figure 4). It is noteworthy to highlight that this result is in agreement with the data obtained by the screening that was preemptively performed to identify which $\mathrm{NAD}^{+}$-biosynthetic enzymatic activities are present in this cell line (Figure 1B). Indeed, this result strengthens the idea that identifying the contribution of each enzyme to $\mathrm{NAD}^{+}$biosynthesis in various tissue/cell types, is crucial for the rational design of successful therapeutic strategies aimed at modulating $\mathrm{NAD}^{+}$metabolism [49]. Currently, no specific inhibitors for NRK are available yet: their identification might prove useful in combined therapies to reduce $\mathrm{NAD}^{+}$levels in tumors, depending on the relative contribution of this enzyme.

Our data show for the first time that $\mathrm{NAD}^{+}, \mathrm{NMN}$ and $\mathrm{NR}$ are present in ascitic exudates. $\mathrm{NAD}^{+}$has been previously detected in mammalian plasma and fluids [26]. Regarding NMN, few data are available to prove its presence in murine plasma [27, 51]. This study represents the first report of NR detection in murine fluids.

The detection of the extracellular $\mathrm{NAD}^{+}, \mathrm{NMN}$ and NR was obviously very important for our working hypothesis. Interestingly, by inhibiting CD73 activity, an increase in extracellular $\mathrm{NAD}^{+}$and/or NMN was expected (see Figure 1A): instead, this was not documented by our measurements in ascitic exudates (Figure 4). Nevertheless, the interpretation of these results is difficult since the levels of these nucleotides may also reflect the activity of ectoenzymes other than CD73, as well as the intracellular content of the same nucleotides. Indeed, $\mathrm{NAD}^{+}$and NMN concentrations in the ascitic exudates seems to correlate with their intratumoral concentration
(Figure 4). The marked decrease in the levels of extracellular $\mathrm{NAD}^{+}$and ATP that was obtained with the combination of FK866 and APCP (Figure 4) might prove beneficial from a therapeutic prospective and also provides mechanistic insights on the well-known role of the tumor microenvironment in the control of tumor growth and tumor-related inflammation. In this context, extracellular $\mathrm{NAD}^{+}$and ATP have been demonstrated to represent pro-inflammatory stimuli $[52,53]$. Specifically, extracellular $\mathrm{NAD}^{+}$levels in the low micromolar range, such as those detected in our ascitic exudates, effectively stimulate innate immune responses [52].

In a previous study of human ovarian cancer xenografts generated by subcutaneous injection of A2780 cells in mice, the expression of the proliferation marker, Ki67, within the tumors was significantly reduced by FK866 [54]. In our model (OVCAR-3 xenografts) the use of FK 866 alone did not reduce the number of Ki- $67^{+}$cells, or significantly affect animal survival (possibly due to the lower dose of FK866 used in our study, i.e. $10 \mathrm{mg} / \mathrm{Kg}$ instead of $15 \mathrm{mg} / \mathrm{Kg}$ [54]). However, a reduction in tumor cell proliferation (as revealed by immunohistochemistry on tumor sections), accompanied by a consistent increase in survival, was observed in response to the coadministration of FK866 together with APCP (Figure 6A, 6C). These effects nicely correlated with the observed reductions in $\mathrm{NAD}^{+}$and $\mathrm{ATP}$ levels. The lower number of proliferating cells in tumors from mice treated with FK866 plus APCP was also accompanied by the presence of larger necrotic areas (Figure 6B).

CD73 is emerging as an appealing target in cancer therapy, especially for its key role as an immunosuppressive factor within the tumor microenvironment. Small molecular inhibitors and monoclonal antibodies against CD73 have been recently developed [55, 56], and our data indicate that combinations of NAMPT inhibitors and CD73-targeting agents might prove clinically effective.

Regarding the translational relevance of our results, recently it has been demonstrated that, in line with what reported for other tumor tissues [30-37, 57], CD73 is associated with poor prognosis in high-grade serous ovarian cancer, representing a prognostic marker of patient survival [58]. From a study on patients affected by EOC (subdivided on the basis of different clinicopathologic variables), it was inferred that tumors exhibit various levels of CD73 expression. In that study, $29.9 \%$ of the patients had $\mathrm{CD} 73^{-}$tumors, and the rest had a variable level of CD73 expression, with CD73 being more frequently expressed in mucinous and in clear cell carcinoma, compared to serous and endometriod adenocarcinoma [59]. Thus, a personalized treatment approach that takes into account CD73 expression could be considered. Unexpectedly, in the latter study, the $\mathrm{CD}^{2} 3^{+}$ovarian cancer group (mostly including patients with mucinous adenocarcinoma) showed better prognosis and the authors 
speculated that cell differentiation stage had more influence on the prognosis than the adverse effect of CD73 [59].

In another clinical study, it was demonstrated that CD73 is highly expressed by mesenchymal-like and also, to a lower level, by epithelial-like cells isolated from ascites or cancer tissue from patients with EOC [60]. In fact, an advantage of the combination of NAMPT inhibitors with CD73 inhibitors is that their synergism could be achieved regardless of whether NR production from extracellular $\mathrm{NAD}^{+} / \mathrm{NMN}$ is catalyzed by $\mathrm{CD} 73$ harbored on epithelial or on mesenchymal-like cells. Finally, it was reported that $\mathrm{CD} 117^{+} / \mathrm{CD} 73^{+}$fibroblast-like stromal cells are significantly associated with poor clinical manifestations and poor survival probability in ovarian carcinomas, and further studies of $\mathrm{CD}^{+} 3^{+}$stromal celltargeting therapies in EOCs were thought to be important [38]. Thus, targeting CD73 could prove beneficial under several respects, directly targeting $\mathrm{NAD}^{+}$biosynthesis in the malignant epithelial cells (as those used in our study), but also preventing CD73 activity on the stromal cells that are present within the tumor, which might contribute to the generation of NR and adenosine in the tumor extracellular microenvironment and thereby promote tumor growth [61].

In conclusion, our study demonstrates that the CD73 inhibitor APCP can enhance the antitumor activity of FK866 in ovarian cancer cells. The potentiation of FK866 with APCP occurs through an enhancement of the depletion of $\mathrm{NAD}^{+}$and ATP that is initiated by FK866, ultimately resulting in tumor growth inhibition and necrotic tumor cell death. This study provides the proofof-concept that combining NAMPT and CD73 inhibitors might prove clinically beneficial and warrants further investigations of this approach in other models and then, potentially, in clinical trials.

\section{MATERIALS AND METHODS}

\section{Drugs}

All chemicals were purchased from Sigma (Milan, Italy), unless otherwise stated. FK866 was in part generously provided by the NIMH Chemical Synthesis and Drug Supply Program and in part purchased from Sigma. NR was enzymatically synthesized from $\mathrm{NAD}^{+}$as described [25].

\section{Cell culture}

OVCAR-3 cells (human ovarian cancer cells), transfected with fire fly-luciferase, obtained as described in [62] were grown in RPMI1640 supplemented with 10\% fetal calf serum, penicillin $(100 \mathrm{U} / \mathrm{ml})$ and streptomycin $(100 \mu \mathrm{g} / \mathrm{ml})$ at $37^{\circ} \mathrm{C}$ in a humidified atmosphere with $5 \% \mathrm{CO}_{2}$.

\section{CD73 and NRK1 siRNA gene silencing}

OVCAR-3 cells were transfected with Stealth ${ }^{\mathrm{TM}}$ RNAi (Life Technologies Italia, Monza, Italy) targeting human CD73 (Oligo ID: HSS101578) or with Mission esiRNA (Sigma) targeting human NRK1 (Oligo ID: HU09786-1). Cells were electroporated with $2 \mu \mathrm{M}$ duplex siRNA with the Nucleofector System, using the Cell Line Nucleofector Kit V, program V-005, following the manufacturer's instructions. As control, OVCAR-3 cells were transfected with Stealth ${ }^{\mathrm{TM}}$ RNAi Negative Control Duplex (Life Technologies Italia) for CD73 or with Mission negative control (Sigma) for NRK1. Cells were seeded as follows: $2 \times 10^{5}$ onto $35 \times 10 \mathrm{~mm}$ tissue culture dishes for mRNA quantification; $2 \times 10^{5}$ cells/well in 12 -well plates for the determination of intracellular $\mathrm{NAD}^{+}$levels; $5 \times 10^{3}$ cells/ well in $96-$-well plates for viability assays. All experiments were carried out $24 \mathrm{~h}$ after transfection.

\section{qPCR analyses}

Twenty-four h after transfection, total RNA was extracted from OVCAR-3 cells using the RNeasy Micro Plus Kit (Qiagen, Milan, Italy). Quality and quantity of RNA were analyzed using a NanoDrop spectrophotometer (Nanodrop Technologies, Wilmington, DE). cDNA (0.5 $\mu \mathrm{g})$ was synthesized by using iScript cDNA Synthesis Kit (Bio-Rad Laboratories, Milan, Italy). PCR primers were designed by using through Beacon Designer 2.0 Software (Bio-Rad) and their sequences were as follows: hCD73: 5'-GCTCGGCTCTTCACCAAG -3' (forward), 5'-TCAGT CCTTCCACACCATTAT -3' (reverse); hNRK1: 5'-AAG CCCCTTGACACTATATGGA-3' (forward), 5'-TCTGG AGGCTGATAGACCCT-3' (reverse); hGAPDH: 5'-CCTG TTCGACAGTCAGCCG-3' (forward), 5'-CGACCAAA TCCGTTGACTCC -3' (reverse); hHPRT1: 5'-GGTCA GGCAGTATAATCCAAAG-3' (forward), 5'-TTCATTAT AGTCAAGGGCATATCC-3' (reverse).

Statistical analyses of the qPCR were obtained using iQ5 Optical System Softwar version 2.0 (Bio-Rad) based on the $2^{-\Delta \Delta} \mathrm{Ct}$ method, which calculated relative changes in gene expression of the target normalized to GAPDH and HPRT-1. Experiments were repeated 3 times in triplicate.

\section{Western blot analyses}

Twenty-four $\mathrm{h}$ after transfection, level of CD73 expression were evaluated on cell lysates from control and silenced cells by Western Blot analysis, performed as described in [25] and visualized with the following antibodies: anti-CD73 (SAB1306278-40TST, Sigma), anti-vinculin (kindly provided by Prof. E. Turco, University of Torino, Italy). Western blots were developed with the ECL-PLUS kit (GE Healthcare), according to the manufacturer's instructions. Band detection and 
densitometry were performed using the Chemi-Doc System and the quantity one software package (Bio-Rad).

\section{Determination of intracellular NAD ${ }^{+}$levels}

OVCAR-3 cells (not transfected, transfected with negative control siRNA or with siRNA targeting CD73 or NRK1) were plated at a density of $10^{5}$ cells/well in 12-well plates and cultured in $500 \mu \mathrm{l}$ of complete RPMI1640 in the presence or absence of $30 \mathrm{nM}$ FK866 and, depending on the experimental setting, with or without $5 \mu \mathrm{M}$ dypiridamole, and supplemented twice a day (at 9 am and at $6 \mathrm{pm}$ ) for 2 days, with or without $10 \mu \mathrm{M}$ of NMN or NR. Then, cells were harvested and lysed in $0.05 \mathrm{ml}$ of 0.6 M PCA at $4{ }^{\circ} \mathrm{C}$. Cell extracts were centrifuged for $3 \mathrm{~min}$ at $16,000 \mathrm{xg}$, the supernatants were collected and an aliquot was diluted 20 -fold in $100 \mathrm{mM}$ sodium phosphate buffer, $\mathrm{pH}$ 8.0, for determination of $\mathrm{NAD}^{+}$content, as described [63]. $\mathrm{NAD}^{+}$values were normalized to protein concentrations, determined by Bradford assay [64].

\section{Cell viability assays}

OVCAR-3 cells $\left(5 \times 10^{3} /\right.$ well in 96 -well plates; not transfected, transfected with negative control siRNA or with siRNA targeting CD73 or NRK1) were incubated in the presence or absence of $30 \mathrm{nM} \mathrm{FK866,} \mathrm{with} \mathrm{or} \mathrm{without}$ $1 \mu \mathrm{M}$ adenosine $5^{\prime}-(\alpha, \beta$-methylene)diphosphate (APCP), with or without $5 \mu \mathrm{M}$ dypiridamole, and, supplemented (or not) twice a day (at 9 am and at $6 \mathrm{pm}$ ) for 2-3 days, with or without $10 \mu \mathrm{M}$ NMN or NR. Cell viability was measured as described [25].

\section{Assays of ectocellular AMP-degrading enzyme activity}

The ectocellular enzymatic activity of CD73 was assayed by incubating not transfected, transfected with negative control siRNA or with CD73-targeting siRNA, OVCAR-3 intact cells $\left(0.5 \times 10^{6}\right.$ in $0.5 \mathrm{ml}$ of phosphate buffered saline, PBS) in the presence of the substrate AMP $(0.2 \mathrm{mM})$. At various times $(0,1,2.5$ and $5 \mathrm{~min})$, $100-\mu \mathrm{l}$ aliquots of the incubations were withdrawn, briefly centrifuged, and $2.5 \%$ trichloroacetic acid (TCA) was added to $90-\mu 1$ supernatants. Samples were centrifuged and the excess TCA removed with diethylether. The amounts of adenosine produced were determined by the phosphate HPLC analysis described previously [25].

\section{Assay of ectocellular CD38 activity on $\mathrm{NAD}^{+}$or NGD $^{+}$}

Ectocellular enzymatic activities of CD38 were assayed by incubating $0.5 \times 10^{6}$ OVCAR- 3 intact cells in $0.5 \mathrm{ml}$ of PBS in the presence of the substrates $\mathrm{NAD}^{+}$or $\mathrm{NGD}^{+}(0.5 \mathrm{mM})$. At various times $(0,10$ and $60 \mathrm{~min})$, $100-\mu l$ aliquots of the incubations were withdrawn, briefly centrifuged, and $2.5 \%$ trichloroacetic acid (TCA) was added to $90-\mu 1$ supernatants. Samples were centrifuged and the excess TCA removed with diethylether. The production of ADPR (from NAD ${ }^{+}$) or cGDPR (from $\mathrm{NGD}^{+}$) were determined by the phosphate HPLC analysis described previously [63].

\section{Assays of NAMPT, NRK, NAPRT and QAPRT activities}

OVCAR-3 cells were incubated (or not) with 30 nM FK 866 for $24 \mathrm{~h}$. Approximately $5 \times 10^{6}$ OVCAR- 3 cell pellets were homogenized with $0.2 \mathrm{ml}$ buffer consisting of $50 \mathrm{mM}$ TRIS/HCl, pH 7.5, $0.15 \mathrm{M} \mathrm{NaCl}, 1 \mathrm{mM}$ dithiothreitol, $1 \mathrm{mM}$ phenylmethanesulfonyl fluoride, and $0.002 \mathrm{mg} / \mathrm{ml}$ each of leupeptin, antipain, chymostatin and pepstatin. Homogenates were centrifuged at $20,000 \mathrm{x} \mathrm{g}$ for $10 \mathrm{~min}$ at $4^{\circ} \mathrm{C}$, and the supernatants were immediately used for the assays of enzymatic activities. The simultaneous measurement of the four enzymatic activities was performed by using the coupled fluorometric assay described in [49]. The enzymes' activity was referred to the protein concentration determined according to [63].

\section{Flow cytometric analysis}

OVCAR-3 cells $(0.4 \times 106)$ were harvested, washed once with PBS buffer and incubated for $20 \mathrm{~min}$ at $37^{\circ} \mathrm{C}$ in the presence (or absence) of the anti-CD73 antibody (Sc130006, Santa Cruz Biotechnology, Inc., Santa Cruz, CA, USA), in PBS containing 0.5\% FBS. Cells were washed once with PBS, and incubated for $20 \mathrm{~min}$ at $37^{\circ} \mathrm{C}$ in the presence of an anti-mouse secondary antibody conjugated with Alexa-576, in PBS containing 0.5\% FBS. Cells were washed twice with PBS and analyzed using a FACS Calibur flow cytometer (Becton Dickinson) by acquiring 10,000 events.

\section{In vivo treatment}

Athymic nude mice were intraperitoneally (ip) inoculated with $1.5 \times 10^{5}$ OVCAR-3 cells transfected with firefly luciferase. The in vivo bioluminescence using IVISTM Imaging System, performed 5 days after inoculation, allowed us to monitor tumor development and randomize the mice in the different groups of treatment. Thus, animals were divided in four groups, treated as follows: vehicle $(0.05 \%$ dimethyl sulfoxide, DMSO), FK866 (10 mg/Kg administered ip once a day for 28 days), APCP (15 mg/Kg administered ip every other day for 28 days) or the combination of the two molecules. On the day of sacrifice, tumor samples, heart and liver were collected and fixed in $20 \%$ buffered formalin, routinely processed and embedded in paraffin. One part of some of the lesions was embedded in OCT, frozen 
in liquid nitrogen and stored at $-80^{\circ} \mathrm{C}$. Ascites exudates were collected, centrifuged to discard possible cells and immediately frozen in liquid nitrogen. In a second trial, conducted as above, animals were sacrificed when they showed signs of poor health to evaluate survival.

\section{Determination of $\mathrm{NAD}^{+}, \mathrm{NMN}, \mathrm{ATP}$ and NR levels in samples from treated animals}

Nucleotides were extracted from tumor, liver and heart as described in [46]. Perchloric acid (PCA, $0.6 \mathrm{M}$, final concentration, for $\mathrm{NAD}^{+}, \mathrm{NMN}$ and $\mathrm{NR}$ determination) or trichloroacetic acid (TCA, 5\% v/v, final concentration, for ATP determination) was added to the ascitic exudates for deproteinization: samples were then neutralized by adding $\mathrm{K}_{2} \mathrm{CO}_{3}$ (for PCA) or by extraction with diethyl ether (for TCA). NAD ${ }^{+}$and ATP levels in tumors were determined as described [46], and normalized to tissue weight (for tumor, liver and heart). ATP levels in ascitic exudates were measured on neutralized extracts with an ATP determination kit (Invitrogen, Carlsbad, CA) following the manufacturer's instruction. Twenty- $\mu 1$ of the extract were added to $180 \mu \mathrm{l}$ of reaction buffer in each well of a 96-well plate. Luminescence was measured using a FLUOstar OPTIMA (BMG Labtech, Ortenberg, Germany) and ATP concentrations in the samples were calculated from the ATP standard curve.

NMN and NR were measured upon derivatization with acetophenone and spectrofluorometric HPLC analysis. Derivatization was performed by mixing $50 \mu \mathrm{l}$ of the nucleotide extracts with $100 \mu \mathrm{KOH} 1 \mathrm{~N}$ and $50 \mu \mathrm{l}$ acetophenone. After $15 \mathrm{~min}$ incubation at $4^{\circ} \mathrm{C}, 100 \mu \mathrm{l}$ of formic acid was added and the samples were heated for $5 \mathrm{~min}$ at $100^{\circ} \mathrm{C}$. The spectrofluorometric HPLC analysis was carried out as described in [65]. Measurements were performed by using a duplicate sample analyzed in parallel and containing known amounts of NMN and NR spikes.

\section{Immunohistochemical staining of tissues}

Immunohistochemical staining of tissue sections was performed using the Envision System HRP mouse (Dako). Briefly, $5 \mathrm{~mm}$ thick sections were cut from formalin fixed, paraffin embedded blocks, deparaffinized with xylene and rehydrated by passages through decreasing concentrations of ethanol (from $100 \%$ to $70 \%$ ). Endogenous peroxidase activity was blocked by $30 \mathrm{~min}$ incubation at room temperature with methanol containing $3 \% \mathrm{H}_{2} \mathrm{O}_{2}$. Tissue sections were then incubated at $98^{\circ} \mathrm{C}$ for $40 \mathrm{~min}$ in EDTA $1 \mathrm{mM}$ ( $\mathrm{pH} \mathrm{8.0)}$ for antigen retrieval (Sigma). After rinsing in PBS (Sigma), tissue sections were incubated 1 hour at Room Temperature with anti-Ki67 (Dako). Tissue sections were washed twice in PBS and incubated for $30 \mathrm{~min}$ at room temperature with Dako Envision System horse radish peroxidase (HRP) Mouse. After washing in PBS, peroxidase activity was detected by incubating tissue sections for 6-10 min at room temperature with Dako Liquid DAB Substrate Chromogen System (Dako). Tissue sections were counterstained with Mayer's hematoxylin (Sigma). The number of positively stained tumor cells in each lesion was evaluated independently by two investigators. The variation between the results obtained by the two investigators was less than $10 \%$.

Some sections were processed and stained with Hematoxylin/Eosin solution and the necrotic areas were quantified using the Image J program.

\section{Statistical analyses}

All parameters were tested by paired $t$ test or by Two-tailed unpaired $t$ test with 95\% Confidence Interval; $p$ values $<0.05$ were considered significant. In the Figures, only relevant comparisons are shown. The statistical significance of differential survival between experimental groups of animals was determined by Kaplan-Meier curves and Peto's log-rank test by the use of StatDirect statistical software (CamCode, Ashwell, UK). All statistical tests were two-sided, and $P$ values less than .05 were considered statistically significant.

\section{GRANT SUPPORT}

This work was supported by Cinque per mille dell'IRPEF-Finanziamento della ricerca sanitaria, "Finanziamento Ricerca Corrente, Ministero Salute" to L.R.; by the FP7 grant PANACREAS, \#256986, to A. Nencioni, A. Nahimana and S.B.; by the AIRC Start-Up grant \#6108 to A.N.; by the Italian Ministry of Health grants GR-2008-1135635 and GR-2011-02347192, to A.N.; by the Compagnia di San Paolo grant R.O.L. 689, to A.N.; by the Fondazione CARIGE, to A.N.; by the Fondazione Umberto Veronesi (to A.N.); and by the University of Genova (A.N. and S.B.). G.B. was a fellow of an Italian Association for Cancer Research grant (n IG 13003).

\section{CONFLICTS OF INTEREST}

The Authors disclose no conflicts of interest.

\section{REFERENCES}

1. Bogan KL, Brenner C. Nicotinic acid, nicotinamide, and nicotinamide riboside: a molecular evaluation of $\mathrm{NAD}^{+}$ precursor vitamins in human nutrition. Annu Rev Nutr. 2008; 28:115-130.

2. Garavaglia S, Bruzzone S, Cassani C, Canella L, Allegrone G, Sturla L, Mannino E, Millo E, De Flora A, Rizzi M. The high-resolution crystal structure of periplasmic Haemophilus influenzae NAD nucleotidase reveals a novel enzymatic function of human CD73 related to NAD metabolism. Biochem J. 2012; 441:131-141. 
3. Rongvaux A, Shea R J, Mulks MH, Gigot D, Urbain J, Leo O, Andris F. Pre-B-cell colony-enhancing factor, whose expression is up-regulated in activated lymphocytes, is a nicotinamide phosphoribosyltransferase, a cytosolic enzyme involved in NAD biosynthesis. Eur J Immunol. 2002; 32:3225-3234.

4. Lau C, Niere M, Ziegler M. The NMN/NaMN adenylyltransferase (NMNAT) protein family. Front Biosci. 2009; 14:410-431.

5. Ruggieri S, Orsomando G, Sorci L, Raffaelli N. Regulation of NAD biosynthetic enzymes modulates NAD-sensing processes to shape mammalian cell physiology under varying biological cues. Biochim Biophys Acta. 2015; 1854:1138-1149.

6. Galli U, Travelli C, Massarotti A, Fakhfouri G, Rahimian R, Tron GC, Genazzani AA. Medicinal chemistry of nicotinamide phosphoribosyltransferase (NAMPT) inhibitors. J Med Chem. 2013; 56:6279-6296.

7. Sampath D, Zabka TS, Misner DL, O'Brien T, Dragovich PS. Inhibition of nicotinamide phosphoribosyltransferase (NAMPT) as a therapeutic strategy in cancer. Pharmacol Ther. 2015; 151:16-31.

8. Montecucco F, Cea M, Bauer I, Soncini D, Caffa I, Lasigliè D, Nahimana A, Uccelli A, Bruzzone S, Nencioni A. Nicotinamide phosphoribosyltransferase (NAMPT) inhibitors as therapeutics: rationales, controversies, clinical experience. Curr Drug Targets. 2013; 14:637-643.

9. Bruzzone S, Parenti MD, Grozio A, Ballestrero A, Bauer I, Del Rio A, Nencioni A. Rejuvenating sirtuins: the rise of a new family of cancer drug targets. Curr Pharm Des. 2013; 19:614-623.

10. Bauer I, Grozio A, Lasigliè D, Basile G, Sturla L, Magnone M, Sociali G, Soncini D, Caffa I, Poggi A, Zoppoli G, Cea M, Feldmann G, et al. The NAD ${ }^{+}$-dependent histone deacetylase SIRT6 promotes cytokine production and migration in pancreatic cancer cells by regulating $\mathrm{Ca} 2^{+}$ responses. J Biol Chem. 2012; 287:40924-40937.

11. Malavasi F, Deaglio S, Damle R, Cutrona G, Ferrarini M, Chiorazzi N. CD38 and chronic lymphocytic leukemia: a decade later. Blood. 2011; 118:3470-3478.

12. Hasmann M, Schemainda I. FK866, a highly specific noncompetitive inhibitor of nicotinamide phosphoribosyltransferase, represents a novel mechanism for induction of tumor cell apoptosis. Cancer Res. 2003; 63:7436-7442.

13. Shackelford RE, Mayhall K, Maxwell NM, Kandil E, Coppola D. Nicotinamide Phosphoribosyltransferase in Malignancy: A Review. Genes Cancer. 2013; 4:447-456. doi:10.1177/1947601913507576.

14. Bruzzone S, Fruscione F, Morando S, Ferrando T, Poggi A, Garuti A, D’Urso A, Selmo M, Benvenuto F, Cea M, Zoppoli G, Moran E, Soncini D, et al. Catastrophic NAD depletion in activated T lymphocytes through Nampt inhibition reduces demyelination and disability in EAE. PLoS One. 2009; 4:e7897.
15. Tan B, Young DA, Lu ZH, Wang T, Meier TI, Shepard RL, Roth K, Zhai Y, Huss K, Kuo MS, Gillig J, Parthasarathy S, Burkholder TP, et al. Pharmacological inhibition of nicotinamide phosphoribosyltransferase (NAMPT), an enzyme essential for NAD biosynthesis, in human cancer cells: metabolic basis and potential clinical implications. J Biol Chem. 2013; 288:3500-3511.

16. Holen K, Saltz LB, Hollywood E, Burk K, Hanauske AR. The pharmacokinetics, toxicities, and biologic effects of FK866, a nicotinamide adenine dinucleotide biosynthesis inhibitor. Invest New Drugs. 2008; 26:45-51.

17. Pogrebniak A, Schemainda I, Azzam K, Pelka-Fleischer R, Nussler V, Hasmann M. Chemopotentiating effects of a novel NAD biosynthesis inhibitor, FK866, in combination with antineoplastic agents. Eur J Med Res. 2006; 11: 313-321.

18. Moore Z, Chakrabarti G, Luo X, Ali A, Hu Z, Fattah FJ, Vemireddy R, DeBerardinis RJ, Brekken RA, Boothman DA. NAMPT inhibition sensitizes pancreatic adenocarcinoma cells to tumor-selective, PAR-independent metabolic catastrophe and cell death induced by $\beta$-lapachone. Cell Death Dis. 2015; 6:e1599.

19. Bajrami I, Kigozi A, Van Weverwijk A, Brough R, Lord CJ, Ashworth A. Synthetic lethality of PARP and NAMPT inhibition in triple-negative breast cancer cells. EMBO Mol Med. 2012; 4:1087-1096.

20. Zoppoli G, Cea M, Soncini D, Fruscione F, Rudner J, Moran E, Caffa I, Bedognetti D, Motta G, Ghio R, Ferrando F, Ballestrero A, Parodi S, et al. Potent synergistic interaction between the Nampt inhibitor APO866 and the apoptosis activator TRAIL in human leukemia cells. Exp Hematol. 2010; 38:979-988.

21. Cea M, Soncini D, Fruscione F, Raffaghello L, Garuti A, Emionite L, Moran E, Magnone M, Zoppoli G, Reverberi D, Caffa I, Salis A, Cagnetta A, et al. Synergistic interactions between HDAC and sirtuin inhibitors in human leukemia cells. PloS One. 2011; 6:e22739.

22. Cagnetta A, Caffa I, Acharya C, Soncini D, Acharya P, Adamia S, Pierri I, Bergamaschi M, Garuti A, Fraternali G, Mastracci L, Provenzani A, Zucal C, et al. APO866 Increases Antitumor Activity of Cyclosporin-A by Inducing Mitochondrial and Endoplasmic Reticulum Stress in Leukemia Cells. Clin Cancer Res. 2015; 21:3934-45.

23. Nahimana A, Aubry D, Breton CS, Majjigapu SR, Sordat B, Vogel P, Duchosal MA. The anti-lymphoma activity of APO866, an inhibitor of nicotinamide adenine dinucleotide biosynthesis, is potentialized when used in combination with anti-CD20 antibody. Leuk Lymphoma. 2014; 55: 2141-2150.

24. Zerp SF, Vens C, Floot B, Verheij M, van Triest B. NAD ${ }^{+}$ depletion by APO866 in combination with radiation in a prostate cancer model, results from an in vitro and in vivo study. Radiother Oncol. 2014; 110:348-354. 
25. Grozio A, Sociali G, Sturla L, Caffa I, Soncini D, Salis A, Raffaelli N, De Flora A, Nencioni A, Bruzzone S. CD73 protein as a source of extracellular precursors for sustained NAD biosynthesis in FK866-treated tumor cells. J Biol Chem. 2013; 288:25938-25949.

26. De Flora A, Zocchi E, Guida L, Franco L, Bruzzone S. Autocrine and paracrine calcium signaling by the CD38/ NAD/cyclic ADP-ribose system. Ann NY Acad Sci. 2004; 1028:176-191.

27. Yoshino J, Mills KF, Yoon MJ, Imai S. Nicotinamide mononucleotide, a key NAD intermediate, treats the pathophysiology of diet- and age-induced diabetes in mice. Cell Metab. 2011; 14:528-536.

28. Bruzzone S, Guida L, Zocchi E, Franco L, De Flora A. Connexin 43 hemi channels mediate $\mathrm{Ca}^{+}$-regulated transmembrane NAD fluxes in intact cells. FASEB J. 2001; $15: 10-12$.

29. Bruzzone S, Franco L, Guida L, Zocchi E, Contini P, Bisso A, Usai C, De Flora A. A self-restricted CD38-connexin 43 cross-talk affects NAD and cyclic ADP-ribose metabolism and regulates intracellular calcium in $3 \mathrm{~T} 3$ fibroblasts. J Biol Chem. 2001; 276:48300-48308.

30. Beavis PA, Stagg J, Darcy PK, Smyth MJ. CD73. A potent suppressor of antitumor immune responses. Trends Immunol. 2012; 33:231-237.

31. Young A, Mittal D, Stagg J, Smyth MJ. Targeting cancerderived adenosine: new therapeutic approaches. Cancer Discov. 2014; 4:879-888.

32. Salmi M, Jalkanen S. Homing-associated molecules CD73 and VAP-1 as targets to prevent harmful inflammations and cancer spread. FEBS Lett. 2011; 585:1543-1550.

33. Stagg J, Divisekera U, McLaughlin N, Sharkey J, Pommey S, Denoyer D, Dwyer KM, Smith MJ. Anti-CD73 antibody therapy inhibits breast tumor growth and metastasis. Proc Natl Acad Sci USA. 2010; 107:1547-1552.

34. Zhang B. CD73. A novel target for cancer immunotherapy. Cancer Res. 2010; 70:6407-6411.

35. Serra S, Horenstein AL, Vaisitti T, Brusa D, Rossi D, Laurenti L, D’Arena G, Coscia M, Tripodo C, Inghirami G, Robson SC, Gaidano G, Malavasi F, et al. CD73-generated extracellular adenosine in chronic lymphocytic leukemia creates local conditions counteracting drug-induced cell death. Blood. 2011;118:6141-6152.

36. Forte G, Sorrentino R, Montinaro A, Luciano A, Adcock IM, Maiolino P, Arra C, Cicala C, Pinto A, Morello S. Inhibition of CD73 improves B cell-mediated anti-tumor immunity in a mouse model of melanoma. J Immunol. 2012; 189: 2226-2233.

37. Colgan SP, Eltzschig HK, Eckle T, Thompson LF. Physiological roles for ecto-5'-nucleotidase (CD73). Purinergic Signal. 2006; 2:351-360.

38. Huang R, Wu D, Yuan Y, Li X, Holm R, Trope CG, Nesland JM, Suo Z. CD117 expression in fibroblasts-like stromal cells indicates unfavorable clinical outcomes in ovarian carcinoma patients. PLoS One. 2014; 9:e112209.

39. Dölle C, Ziegler M. Application of a coupled enzyme assay to characterize nicotinamide riboside kinases. Anal Biochem. 2009; 385:377-379.

40. Okuno E, White RJ, Schwarcz R. Quinolinic acid phosphoribosyltransferase: purification and partial characterization from human liver and brain. J Biochem. 1988; 103:1054-1059.

41. Sahm F, Oezen I, Opitz CA, Radlwimmer B, von Deimling A, Ahrendt T, Adams S, Bode HB, Guillemin GJ, Wick W, Platten $\mathrm{M}$. The endogenous tryptophan metabolite and $\mathrm{NAD}^{+}$ precursor quinolinic acid confers resistance of gliomas to oxidative stress. Cancer Res. 2013; 73:3225-3234.

42. Sauve AA, Munshi C, Lee HC, Schramm VL. The reaction mechanism for CD38. A single intermediate is responsible for cyclization, hydrolysis, and base-exchange chemistries. Biochemistry 1998; 37:13239-13249.

43. Graeff RM, Walseth TF, Fryxell K, Branton WD, Lee HC. Enzymatic synthesis and characterizations of cyclic GDP-ribose. A procedure for distinguishing enzymes with ADP-ribosyl cyclase activity. J Biol Chem. 1994; 269:30260-30267.

44. Nikiforov A, Dölle C, Niere M, Ziegler, M. Pathways and subcellular compartmentation of NAD biosynthesis in human cells. From entry of extracellular precursors to mitochondrial NAD generation. J Biol Chem. 2011; 286: 21767-21778.

45. Del Nagro C, Xiao Y, Rangell L, Reichelt M, O’Brien T. Depletion of the central metabolite NAD leads to oncosismediated cell death. J Biol Chem. 2014; 289:35182351892.

46. Montecucco F, Bauer I, Braunersreuther V, Bruzzone S, Akhmedov A, Lüscher TF, Speer T, Poggi A, Mannino E, Pelli G, Galan K, Bertolotto M, Lenglet S, et al. Inhibition of nicotinamide phosphoribosyltransferase reduces neutrophilmediated injury in myocardial infarction. Antioxid Redox Signal. 2013; 18:630-641.

47. O’Brien T, Oeh J, Xiao Y, Liang X, Vanderbilt A, Qin A, Yang L, Lee LB, Ly J, Cosino E, LaCap JA, Ogasawara A, Williams S, et al. Supplementation of nicotinic acid with NAMPT inhibitors results in loss of in vivo efficacy in NAPRT1-deficient tumor models. Neoplasia. 2013; 15:1314-1329.

48. Dölle C, Skoge RH, Vanlinden MR, Ziegler M. NAD biosynthesis in humans-enzymes, metabolites and therapeutic aspects. Curr Top Med Chem. 2013; 13: 2907-2917.

49. Zamporlini F, Ruggieri S, Mazzola F, Amici A, Orsomando G, Raffaelli N. Novel assay for simultaneous measurement of pyridine mononucleotides synthesizing activities allows dissection of the $\left.\mathrm{NAD}^{+}\right)$biosynthetic machinery in mammalian cells. FEBS J. 2014; 281:5104-5119. 
50. Cantó C, Houtkooper RH, Pirinen E, Youn DY, Oosterveer MH, Cen Y, Fernandez-Marcos PJ, Yamamoto H, Andreux PA, Cettour-Rose P, Gademann K, Rinsch C, Schoonjans $\mathrm{K}$, et al. The $\mathrm{NAD}^{+}$) precursor nicotinamide riboside enhances oxidative metabolism and protects against high-fat diet-induced obesity. Cell Metab. 2012; 15:838-847.

51. Zhao Y, Liu XZ, Tian WW, Guan YF, Wang P, Miao CY. Extracellular visfatin has nicotinamide phosphoribosyltransferase enzymatic activity and is neuroprotective against ischemic injury. CNS Neurosci Ther. 2014; 20:539-547.

52. Bruzzone S, Moreschi I, Guida L, Usai C, Zocchi E, De Flora A. Extracellular $\mathrm{NAD}^{+}$regulates intracellular calcium levels and induces activation of human granulocytes. Biochem J. 2006; 393:697-704.

53. Idzko M, Ferrari D, Eltzschig HK. Nucleotide signalling during inflammation. Nature. 2014; 509:310-317.

54. Jensen MM1, Erichsen KD, Johnbeck CB, Björkling F, Madsen J, Bzorek M, Jensen PB, Højgaard L, Sehested M, Kjær A. [18F] FLT and [18F] FDG PET for noninvasive treatment monitoring of the nicotinamide phosphoribosyltransferase inhibitor APO866 in human xenografts. PLoS One. 2013; 8:e53410.

55. Gao ZW, Dong K, Zhang HZ. The roles of CD73 in cancer. Biomed Res Int. 2014; 2014:460654.

56. Bhattarai S, Freundlieb M, Pippel J, Meyer A, Abdelrahman A, Fiene A, Lee S, Zimmermann H, Yegutkia G, Sträter N, El-Tayeb A, Müller CE. $\alpha, \beta$-Methylene-ADP derivatives and analogs: development of potent and selective ecto5'-nucleotidase (CD73) inhibitors. J Med Chem. 2015; 58:6248-6263.

57. Wang L, Zhou X, Zhou T, Ma D, Chen S, Zhi X, Yin L, Shao Z, Ou Z, Zhou P. Ecto-5'-nucleotidase promotes invasion, migration and adhesion of human breast cancer cells. J Cancer Res Clin Oncol. 2008; 134:365-372.
58. Turcotte M, Spring K, Pommey S, Chouinard G, Cousineau I, George J, Chen GM, Gendoo DM, Haibe-Kains B, Karn T, Rahimi K, Le Page C, Provencher D, et al. CD73 Is Associated with Poor Prognosis in High-Grade Serous Ovarian Cancer. Cancer Res. 2015; 75:4494-4503.

59. Oh HK, Sin JI, Choi J, Park SH, Lee TS, Choi YS. Overexpression of CD73 in epithelial ovarian carcinoma is associated with better prognosis, lower stage, better differentiation and lower regulatory $\mathrm{T}$ cell infiltration. J Gynecol Oncol. 2012; 23:274-281.

60. Ho CM, Chang SF, Hsiao CC, Chien TY, Shih DT. Isolation and characterization of stromal progenitor cells from ascites of patients with epithelial ovarian adenocarcinoma. J Biomed Sci. 2012;19:23.

61. Ljujic B, Milovanovic M, Volarevic V, Murray B, Bugarski D, Przyborski S, Arsenijevic N, Lukic ML, Stojkovic M. Human mesenchymal stem cells creating an immunosuppressive environment and promote breast cancer in mice. Sci Rep. 2013; 3:2298.

62. Pastorino F, Brignole C, Di Paolo D, Nico B, Pezzolo A, Marimpietri D, Pagnan G, Piccardi F, Cilli M, Longhi R, Ribatti D, Corti A, Allen TM, et al. Targeting liposomal chemotherapy via both tumor cell-specific and tumor vasculature-specific ligands potentiates therapeutic efficacy. Cancer Res. 2006; 66:10073-10082.

63. Bruzzone S, De Flora A, Usai C, Graeff R, Lee HC. Cyclic ADP-ribose is a second messenger in the lipopolysaccharidestimulated proliferation of human peripheral blood mononuclear cells. Biochem. J. 2003; 375:395-403.

64. Bradford MM. A rapid and sensitive method for the quantitation of microgram quantities of protein utilizing the principle of protein-dye binding. Anal Biochem. 1976; 72:248-254.

65. Mori V, Amici A, Mazzola F, Di Stefano M, Conforti L, Magni G, Ruggieri S, Raffaelli N, Orsomando G. Metabolic profiling of alternative NAD biosynthetic routes in mouse tissues. PLoS One. 2014; 9:e113939. 